\title{
Hospital Infantil Universitario "Lorencita Villegas de Santos"
}

\author{
Dr. Jesús Alberto Gómez Palacino*
}

El interés por la creación de un Servicio de Maternidad en el Hospital "Lorencita Villegas de Santos", expuesto en varias oportunidades en reuniones de su Junta Directiva, sólo fue intentado en el año 1965, bajo la Presidencia del Sr. Gabriel Restrepo y la Dirección del Dr. Juan Antonio Gómez. Se pretendía para tal fin, la vinculación de la Beneficencia de Cundinamarca, gestión que no tuvo éxito. Siendo presidente de la Junta Directiva el Dr. Camilo Sáenz, en el año 1967, el Dr. Alfredo Bárcenas, miembro de la misma, propuso hacer de la Institución un Hospital General y el Dr. Fernando Serpa, representante de la Presidencia de la República, revivió la idea de la maternidad.

En 1968, el Dr. Juan Antonio Gómez sugirió el nombramiento por parte de la Facultad de Medicina del Colegio Mayor de Nuestra Señora del Rosario, de médicos para la atención obstétrica, aprovechando la instalación de nuevas camas en el piso del Hospital. A instancias del Dr. Gustavo Escallón, Presidente de la Junta Directiva, fue nombrado Coordinador de Obstetricia, el Dr. Jaime Pedraza Gaitán, para entonces adjunto a la cátedra de Ginecología del Hospital de San José.

Durante el año 1969 se llevaron a cabo las reformas locativas necesarias para la atención de los partos, bajo la orientación de los arquitectos del Ministerio de Salud y la consejería de los médicos nombrados, entre otros, los Drs. Jorge Michelsen y Rafael Quiñones, el primero de ellos en calidad de Coordinador de Ginecología. Eran decanos de la Facultad de Medicina del Rosario, los profesores Guillermo Ferguson primero y Arturo Aparicio, a partir del 24 de abril. Este último dirigía la cátedra de Ginecología y Obstetricia en el Hospital de San José pero por su condición de Decano había delegado sus funciones en el Dr. Roberto Jaramillo, docente de la misma cátedra.

El día 12 de enero de 1970, siendo Director el Dr. Jaime Pérez Norsagaray, abrió sus puertas el Hospital para la atención de pacientes embarazadas, cumpliéndose así los objetivos de sus funcionarios en el sentido de

* Profesor Titular - Facultad de Medicina U. del Rosario extender la cobertura obstétrica a la población del noroccidente de la capital y ampliar con la atención de los recién nacidos el Servicio de Pediatría, impulsándose de esta manera su cátedra, la cual para poder satisfacer el entrenamiento de los residentes que eran enviados periódicamente a la Clínica David Restrepo.

Así nació el Departamento de Ginecología y Obstetricia del Hospital Universitario "Lorencita Villegas de Santos", dirigido hasta el año de 1984 por el Dr. Jaime Pedraza Gaitán, más tarde Director Científico de la Institución.

Sus primeras pacientes fueron institucionales; después se formalizó un contrato con el Seguro Social para "prestación de servicios ginecológicos médico-quirúrgicos", servicios que eran practicados por médicos especialistas adscritos al I.S.S., ajenos al Hospital.

Más tarde se contrató también la atención obstétrica, ésta a cargo de los especialistas del Hospital, quiénes eran en su mayoría egresados de la Facultad de Medicina de la Universidad Nacional y unos pocos de la Universidad Javeriana.

El 1o. de febrero de 1970 se integró académicamente el personal médico a la docencia de la Facultad de Medicina del Rosario, de cuyo Departamento de Ginecología y Obstetricia ha dependido; los especialistas concurrían al Hospital de San José a dictar las clases, situación que persistió durante algún tiempo hasta cuando esta actividad se ubicó definitivamente en el Hospital Infantil.

En el año 1970 se iniciaron los programas de especialización en Ginecología y Obstetricia bajo la supervisión de ASCOFAME y el aval académico de la Universidad del Rosario. A partir de entonces 88 médicos han sido certificados como especialistas; 12 de ellos hacen en la actualidad parte de la planta docente del Departamento.

A instancias y bajo el patrocinio de Profamilia, se organizó en el año 1972 un servicio dedicado a la planificación familiar y más concretamente para hacer la inserción de dispositivos intrauterinos. Expertos norteamericanos procedentes de la Universidad de Jhons Hopkins, Baltimore, dictaron un curso, quizá el primero 
en el país, para el entrenamiento en laparoscopia, con fines de esterilización por fulguración tubárica. Mas tarde estos programas fueron asumidos y patrocinados por Ascofame.

En 1984 se firmó el primer convenio entre el Hospital y la Escuela Colombiana de Medicina para recibir alumno de pregrado, contrato que se ha renovado anualmente. En la actualidad sus estudiantes hacen todo el semestre de Ginecología y Obstetricia en el Departamento.

En el año de 1989 se amplió el convenio que permite también la participación de estudiantes de postgrado en las actividades de las Unidades de Investigación en Reproducción Humana y de Medicina Materno-Fetal, a las cuales asisten también estudiantes de la Facultad de Medicina Militar (Clínica San Rafael) y Universidad Javeriana (Hospital de la Samaritana).

Hitos del departamento:

1) El haber sido copartícipes con sus pioneros en el control demográfico del país a través de la planificación familiar.
2) La creación de sus Unidades superespecializadas y sus logros: Unidad de Investigación Clínica en Reproducción Humana, 1982. Unidad de Medicina MaternoFetal, 1989. Unidad de Inmunobiología y Genética, 1991 y Unidad de Oncología Ginecológica, 1991.

3) La realización de tres Simposios Internacionales de Medicina Materno-Fetal: 1990, 1992, 1995.

4) La edición de la Revista GINECOLOGIA Y MEDICINA MATERNO FETAL

5) La obtención del Primer puesto en el concurso promovido por la Sociedad Colombiana de Obstetricia y Ginecología para trabajos de investigación, año 1994.

6) El nivel científico alcanzado gracias a la contribución de todo su personal médico a lo largo de 25 años de labor continuada.

7) Haber logrado la vinculación al Departamento en calidad de asesor y Director Honorario de la Unidad de Inmunobiología y Genética del Doctor Alan Beer, Profesor de la Escuela de Medicina de Chicago. 